\title{
Arsenite removal from water by an iron-bearing Layered Double Hydroxide (LDH)
}

\author{
Q.H. Guo \& Y.W. Cao \\ State Key Laboratory of Biogeology and Environmental Geology \& School of Environmental Studies, \\ China University of Geosciences, Hubei, P.R. China
}

\begin{abstract}
A Mg/Fe-based Layered Double Hydroxide (LDH) intercalated with chloride (Nano iowaite), was synthesized to evaluate its performance for arsenite removal from water. It has a much higher arsenite uptake capacity than other LDHs that are commonly used for water dearsenication. The surface adsorption of the solution arsenite onto the iowaite samples and the anion exchange of the arsenite in solution with chloride, which is originally in the iowaite interlayers, are the primary mechanisms for the uptake of arsenite by iowaite.
\end{abstract}

\section{INTRODUCTION}

Arsenic was ranked among the top 20 highest priority harmful substances by the Agency for Toxic Substances and Disease Registry, but nearly 50 millions of people worldwide are suffering from the hazards of drinking high-arsenic waters. Therefore, the treatment of both arsenic-containing wastewater and high-arsenic drinking water has received substantial attention in countries where arsenic problems occur. In recent years, the use of layered double metal hydroxides (LDHs) for purifying arsenic-containing waters has been reported (Goh et al., 2009; Guo \& Tian, 2013). LDHs, which are also called anion clays, were first discovered as a natural mineral (hydrotalcite) by Hohsteter in 1842 and have a general chemical formula of $\left[\mathrm{M}_{1-\mathrm{x}}^{2+} \mathrm{M}_{\mathrm{x}}^{3+}(\mathrm{OH})_{2}\right]\left(\mathrm{A}^{\mathrm{n}-}\right)_{\mathrm{x} / \mathrm{n}} \cdot \mathrm{mH}_{2} \mathrm{O}$, where $\mathrm{M}^{2+}$ is a divalent cation (typically $\mathrm{Mg}^{2+}, \mathrm{Co}^{2+}, \mathrm{Ni}^{2+}, \mathrm{Zn}^{2+}$, or $\mathrm{Mn}^{2+}$ ) $\mathrm{M}^{3+}$ is a trivalent cation (typically $\mathrm{Al}^{3+}$, $\mathrm{Fe}^{3+}, \mathrm{Cr}^{3+}$, or $\mathrm{Ga}^{3+}$ ), and $\mathrm{A}^{\mathrm{n}-}$ is an anion (typically $\mathrm{OH}^{-}, \mathrm{Cl}^{-}, \mathrm{NO}_{3}^{-}, \mathrm{CO}_{3}^{2-}$, or $\mathrm{SO}_{4}^{2-}$ ) (Rives and Ulibarri, 1999). These hydroxides have large surface areas, huge numbers of exchangeable anions within their interlayer regions, and relatively weak interlayer bonding (Zaneva \& Stanimirova, 2004).

In this study, an iron-bearing LDH, Nano-iowaite, was tested for its arsenite uptake capacity in view that among major arsenic species, arsenite is much more toxic than the others. The experimental results indicate that Nano-iowaite performed better than many other commonly used sorbents with respect to solution dearsenication under similar experimental conditions (e.g. the mass ratio of solution arsenic to sorbent). Iron-bearing LDH is promising to be used in arsenic removal for either natural arsenic-rich waters or contaminated high-arsenic waters.

\section{METHODS}

\subsection{Synthesis of iowaite}

The nanocrystalline Mg-Fe(III) LDH (denoted by Nano-iowaite) was synthesized via fast coprecipitation followed by hydrothermal treatment. A mixed salt solution comprising $20 \mathrm{mmol}$ of $\mathrm{MgCl}_{2} \cdot 6 \mathrm{H}_{2} \mathrm{O}$ and $10 \mathrm{mmol}$ of $\mathrm{FeCl}_{3} \cdot 6 \mathrm{H}_{2} \mathrm{O}$ was promptly added to $50 \mathrm{~mL}$ of $1.4 \mathrm{M} \mathrm{NaOH}$ with nitrogen purging and vigorous stirring. The iowaite slurry was centrifuged at $4000 \mathrm{r} \mathrm{min}^{-1}$ for $10 \mathrm{~min}$, washed three times with Nanopure water, and finally dispersed in Nanopure water. The resulting aqueous suspension was then hydrothermally treated in a stainless-steel autoclave at $80^{\circ} \mathrm{C}$ for $4 \mathrm{~h}$. After air-cooling, a stable homogeneous iowaite suspension (the product) was further freeze-dried at $-20^{\circ} \mathrm{C}$ to avoid aggregation. The synthesized iowaite samples were kept in a desiccator to prevent the possible sorption of atmospheric $\mathrm{CO}_{2}$ and moisture.

\subsection{Batch tests}

The arsenite removal experiments were performed using the batch sorption technique by reacting $100 \mathrm{~mL}$ arsenite solutions of various initial concentrations (from 0.15 to $750 \mathrm{mg} \mathrm{L}^{-1}$ ) with $0.2 \mathrm{~g}$ of synthetic iowaite. During the experiments, the sample bottles were sealed and placed in a constant-temperature water bath shaker at $25^{\circ} \mathrm{C}$ for a predetermined period. After the sorption experiments, the solution samples were decanted from the bottles, centrifuged and filtered through a $0.02-\mu \mathrm{m}$ microporous membrane. 


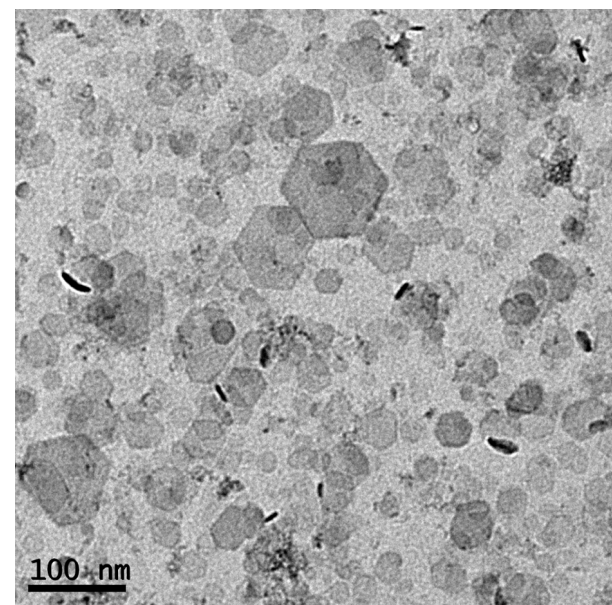

Figure 1. TEM image of synthetic Nano-iowaite.

\section{RESULTS AND DISCUSSION}

\subsection{Characteristics of synthetic iowaite}

Elemental analysis reveals that the $\mathrm{Mg} / \mathrm{Fe}$ molar ratio of synthetic Nano-iowaite is 2.57 , almost the same as its designed ratio (i.e., the molar ratio [2.50] of their starting salts). Nano-iowaite has a narrow particle size distribution (166-675 nm with an equivalent hydrodynamic diameter of $386 \mathrm{~nm}$ ), as demonstrated by the PCS analysis, and its BET specific surface area is $124.6 \mathrm{~m}^{2} \mathrm{~g}^{-1}$. TEM analysis shows that the stable suspensions of Nano-iowaite are monodispersed nanoparticles with a well-shaped hexagonal form (Fig. 1).

\subsection{Arsenite removal by iowaite and the possible mechanisms involved}

The sorption isotherms of arsenite sorbed on Nanoiowaite can be well fitted by the Freundlich and Langmuir models. By extrapolating the Langmuir equation, the sorption maxima of Nano-iowaite for arsenite was calculated to be $263.2 \mathrm{mg} \mathrm{g}^{-1}$. This high capacity of arsenite uptake can be attributed to the narrow particle size distribution and large surface area of Nano-iowaite.

According to the analyses of arsenite and chloride in solution after the sorption reaction, the increment of the solution chloride concentration is positively related to the decrement of the solution arsenite concentration (Fig. 2). Thus, the anion exchange between the arsenite in solution and the chloride that was originally intercalated into the interlayers of the iowaite samples was the primary mechanism for the uptake of arsenite by iowaite. The sorbed arsenite basically binds to the iowaite surface or within its interlayers by forming an outer-sphere complex; that is, the driving force for arsenite sorption onto/into iowaite is likely the Coulombic attraction between arsenite and the positively charged layers of iowaite. However, it cannot

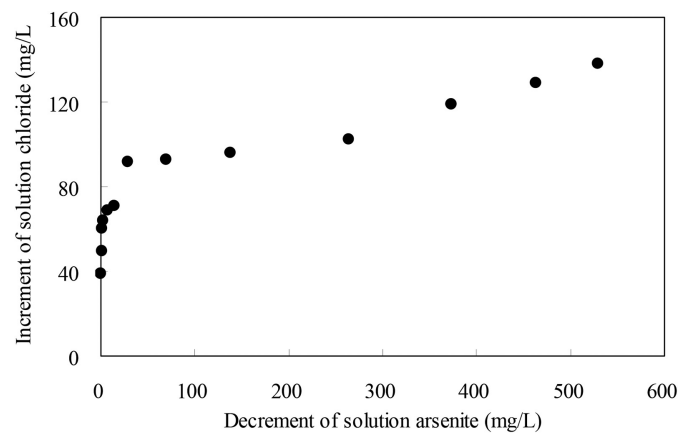

Figure 2. Variations in the increment of chloride vs. the decrement of arsenite in the solutions reacted with Nano-iowaite.

be ruled out that the inner-sphere complexation of arsenite with certain functional groups on the layers of iowaite may also occur and form a more stable and stronger arsenite bond.

\section{CONCLUSIONS}

The experimental work conducted in this study indicates that iowaite, an iron-bearing $\mathrm{LDH}$, can be used to effectively remove arsenite from aqueous solution. The nanocrystallization of iowaite via fast coprecipitation followed by hydrothermal treatment helps to enhance its dearsenication capacity. Nano-iowaite performed better than many other commonly used sorbents with respect to solution dearsenication under similar experimental conditions.

\section{ACKNOWLEDGEMENTS}

This study was financially supported by the National Natural Science Foundation of China (grant numbers 41572335 and 41772370 ) and the research program of State Key Laboratory of Biogeology and Environmental Geology of China (No. GBL11505).

\section{REFERENCES}

Goh, K.-H., Lim, T.-T. \& Dong, Z. 2009. Enhanced arsenic removal by hydrothermally treated nanocrystalline $\mathrm{Mg} / \mathrm{Al}$ layered double hydroxide with nitrate intercalation. Environ. Sci. Technol. 43(7): 2537-2543.

Guo, Q. \& Tian, J. 2013. Removal of fluoride and arsenate from aqueous solution by hydrocalumite via precipitation and anion exchange. Chem. Eng. J. 231: 121-131.

Rives, V. \& Ulibarri, M.A.A. 1999. Layered double hydroxides (LDH) intercalated with metal coordination compounds and oxometalates. Coord. Chem. Rev. 181(1): 61-120.

Zaneva, S. \& Stanimirova, T. 2004. Crystal chemistry, classification position and nomenclature of Layered Double Hydroxides. Bulgarian Geological Society, Annual Scientific Conference "Geology 2004”, pp. 110-112. 